\title{
CONTAMINAC̣ÃO POR MERCÚRIO EM SEDIMENTO E EM MOLUSCOS DO PANTANAL, MATO GROSSO, BRASIL
}

\author{
Luiz M. Vieira ${ }^{1}$ \\ Cleber J.R. Alho ${ }^{2}$ \\ Geraldo A.L. Ferreira ${ }^{3}$
}

\begin{abstract}
MERCIRY CONTAMINATION IN SEDIMENT AND IN MOLLIISCS OF PANTA. NAI.. MATO Grosso. Brazil. The total level of mereury detected in the sediment and in the tissues of molluses from the Bento Gomes basin, although low, have shown that the mercury used in the gold mining activities in the Pocone wetlands has contaminated those aquatic habitats in Pantanal. From 69 sediment samples analyzed, $26 \%(\mathrm{~N}=18)$ have shown levels ranging from 0.01 to $0.25 \mu \mathrm{g} . \mathrm{g}^{-1}$ of mercury (moist weight). Mereury levels analyzed in 54 samples of molluse tissues (Ampullaria scalaris Orbigny. 1835; A. canaliculata Lamarck, 1819 and Marisa planogyra Pilsbry. 1933) have shown that $30 \%(\mathrm{~N}=16)$ were contaminated with levels ranging from 0.02 to $1.16 \mu \mathrm{g} \cdot \mathrm{g}^{-1}$ moist weight. This study shows that the mercury used in digs for gold mining and released into the environment has reached the habitats of Pantanal spread from the sediment into the molluses living in the region.
\end{abstract}

KEY WORDS. Molluses, biomagnification. contaminants, mercury, sediment

A garimpagem de ouro, com uso intensivo de mercúrio, estabelecida no início dos anos 80 na bacia do rio Paraguai, principalmente no município de Poconé (Mato Grosso, Brasil), apresenta elevado potencial de contaminação do sedimento e biota aquática da planície do Pantanal. O problema se reveste ainda de maior relevância pelo risco de contaminação de ecossistemas de países vizinhos à jusante na bacia.

Para cada quilograma de ouro retirado são utilizados de 1,32 a 2,00kg de mercúrio (PFeiffer et al. 1989a,b; MaLlas \& BENDICTO 1986), dos quais $45 \%$ é carreado para os rios e $55 \%$ para a atmosfera (PFEIFFER op. cit.), no processo final de queima do amálgama e posteriormente retorna aos sistemas aquáticos através de precipitações pluviométricas. Incorporado ao sistema aquático na forma inorgânica $\left(\mathrm{Hg}^{\circ}\right.$ - mercúrio metálico), desloca-se para o sedimento, onde pode ocorrer a metilação (JENSEN \& JERNELOV 1969), dando origem ao metilmercúrio que, além de tóxico e persistente, se acumula nos organismos e se magnifica na

1) Centro de Pesquisa Agropecuária do Pantanal, Empresa Brasileira de Pesquisa Agropecuária. Caixa Postal 109. 79320-970 Corumbá, Mato Grosso do Sul. Brasil.

2) Fundo Mundial para a Natureza (WWF-Brasil). SHIS EQQL 6/8 Conjunto E $2^{\circ}$ andar. $71620-430$ Brasilia. Distrito Federal, Brasil.

3) Departamento de Química. Universidade de Brasília. Caixa Postal 0463. $70910-970$ Brasília. Distrito Federal, Brasil. 
cadeia alimentar. No sedimento vivem muitas comunidades bentônicas que, alimentando-se de detritos contaminados por mercúrio, podem transferi-lo aos peixes por ingestão (EPA 1972), e estes contaminarem o homem pelo consumo. O sedimento contaminado é fonte potencial dinâmica de mercúrio (SEI 1978) para a água e para a biota aquática durante 10 a 100 anos (BRAILE \& CAVALCANTI 1979). Isso significa que, mesmo com a paralisação da fonte emissora, há ainda consideráveis quantidades de mercúrio absorvidas ao sedimento (REIMERS et al. 1974; CALlister et al. 1986) e que podem ser transferidas e incorporadas à biota, dependendo das condições físicas, químicas e biológicas do ambiente aquático (LORING 1975; Clifton \& Vivian 1975; CALlister et al. 1986). KUdO \& MORTIMER (1979) verificaram experimentalmente que a concentração de mercúrio nos peixes, proveniente do sedimento, foi nove vezes superior à acumulada a partir da água.

O monitoramento da poluição de rios através de análise de sedimento iniciou-se na Holanda em 1960. A avaliação dos níveis de mercúrio no sedimento de rios, atualmente um indicador amplamente generalizado, inclusive para áreas de importância ecológica ganhou relevância após a demonstração de que a maior proporção de mercúrio em tecido muscular de peixes é metilmercúrio (WESTOO 1972; HEDERSON et al. 1972; BISHOP \& NEARY 1974) e que o sedimento é capaz de metilar mercúrio a partir de formas inorgânicas (JENSEN \& JERNELOV 1969). Antes era consensual que o mercúrio no sedimento não representasse ameaça ao ambiente aquático (RICHINS \& RISSER 1975).

O uso de organismos como indicadores biológicos de poluição ambiental tem a vantagem de estimar as disponibilidades do poluente para as biomassas de diferentes regiões (PHILLIPS 1977). Os moluscos são considerados bons indicadores para metais pesados e para comparações de fatores de concentração (HANNERS 1968). Muitos autores têm usado diferentes gastrópodos para monitorar contaminação mercurial em sistemas de água doce (ZADORY \& MULLER 1981) com base no seu potencial de acumulação de altos níveis de mercúrio, o que geralmente evidencia as condições toxicológicas dos sistemas aquáticos. Sendo sedentários, refletem muito bem as condições locais de contaminação, além de serem abundantes e de larga distribuição geográfica nos sistemas aquáticos do Pantanal. Há forte correlação entre a concentração de mercúrio total nos moluscos e os níveis no sedimento (Hildebrand et al. 1980, apud MiKaC et al. 1985).

O objetivo desta pesquisa foi avaliar o potencial de acumulação de mercúrio no sedimento e nos moluscos da bacia de drenagem do rio Bento Gomes, no Pantanal, tendo em vista sua futura utilização como parâmetros indicadores de poluição nessa região.

\section{MATERIAL E MÉTODOS}

Após sobrevôo da bacia hidrográfica do rio Bento Gomes (1640'S, $57^{\circ} 12^{\prime} \mathrm{W}$ ), dreno coletor principal das mic robacias onde se localizam os garimpos de ouro de Poconé, foram demarcadas oito estações de coleta de sedimento, localizadas desde a cabeceira até o cruzamento do Rio Bento Gomes com a Estrada 
Transpantaneira, no baixo Pantanal (Mato Grosso). Em cada estação foram colhidas três amostras de sedimento, em cada uma das coletas realizadas em agosto/89, novembro-dezembro/89 e junho/90. O coletor do tipo "core", constituído de um tubo coletor de acrílico e as partes acessórias de material inoxidável. As amostras corresponderam ao nível do sedimento até $20 \mathrm{~cm}$ de profundidade. Estas foram acondicionadas individualmente, em sacos de polietileno etiquetados e transportadas para o laboratório em caixas térmicas contendo gelo. No laboratório, as amostras foram armazenadas e conservadas em congelador a $-18^{\circ} \mathrm{C}$. Para a análise, as amostras foram descongeladas à sombra, sendo inicialmente secas ao ar livre e depois em estufa a $50^{\circ} \mathrm{C}$. Ao atingirem a temperatura ambiente, as amostras foram passadas por peneira inoxidável com $0,27 \mathrm{~mm}$ de abertura de malha.

Amostras de aproximadamente um grama de sedimento foram digeridas em mistura de $\mathrm{HNO}_{3}: \mathrm{H}_{2} \mathrm{SO}_{4}$ (concentrados e na proporção de 1:1), em balões de vidro de borosilicato de $250 \mathrm{ml}$, com juntas esmerilhadas, acoplados em condensadores de vidro, com circulação de água sob refluxo. Após o período de digestão a frio, de no mínimo 30 minutos, introduziu-se aquecimento gradual, até aproximadamente $100^{\circ} \mathrm{C}$. Utilizou-se $\mathrm{KMnO}_{4}$ como oxidante e cloreto de hidroxilamina para neutralizar o excesso de acidez. O agente redutor de mercúrio foi $\mathrm{SnCl}_{2}$ a $10 \%$ em $\mathrm{H}_{2} \mathrm{SO}_{4}$ 18N. Maiores detalhes podem ser encontrados em PoncE et al. (1990).

As determinações de mercúrio total no sedimento foram realizadas pela técnica de espectrofotometria de absorção atômica computadorizada SCHIMADZU, modelo AA-660, equipado com lâmpada de catodo oco de mercúrio, com feixe óptico alinhando uma célula de vidro com janelas de quartzo e ajustado ao comprimento de onda de $253,7 \mathrm{~mm}$.

Os níveis de mercúrio total no sedimento, expressos em $\mu \mathrm{g} \cdot \mathrm{g}^{-1}$ de peso seco foram registrados após ajustamento numa curva padrão de calibração e correção das leituras dos brancos. A inexistência de interferência de matriz foi testada através de uma curva e calibração com adição padrão. Na ausência de padrões de referência, a precisão e exatidão da técnica foram avaliadas por testes de recuperação de mercúrio.

Três espécies de moluscos da família Ampullariidae, Ampullaria canaliculata, A. scalaris e Marisa planogyra, foram coletadas manualmente no Rio Bento Gomes (entroncamento com a Estrada Transpantaneira) e no córrego Piraputanga. no Pantanal (Mato Grosso), nas três épocas referidas anteriormente para o sedimento. Essas espécies de moluscos foram selecionadas por serem presas do gavião-caramujeiro - Rosthramus sociubilis (Viellot, 1877) - e do carão - Aramus guarauna (Linnaeus, 1766), aves que vivem nas proximidades de áreas alagadas no Pantanal. Após a captura, os moluscos foram colocados em sacos plásticos etiquetados e acondicionados em caixas térmicas contendo gelo e transportados ao laboratório. No laboratório foram conservados e armazenados em congelador a $-18^{\circ} \mathrm{C}$. Para as análises de mercúrio total nos moluscos, foram utilizadas apenas as partes moles e seguiu-se a mesma técnica descrita para o sedimento. Os níveis de mercúrio nos moluscos foram expressos em $\mu \mathrm{g} \cdot \mathrm{g}^{-1}$ de peso úmido. 
Os reagentes utilizados nas análises de mercúrio total foram: $\mathrm{H}_{2} \mathrm{SO}_{4}$ marca MicroQuímica para Laboratórios Ltda., P.A.; $\mathrm{NHO}_{3}$ Synth, P.A.; $\mathrm{KMnO}_{4}$ Grupo Química P.A., ACS; Cloreto de Hidroxilamina, Vetec Química Fina, P.A.; $\mathrm{SnCl}_{2}$, Grupo Química P.A., ACS. Todas as análises foram realizadas nos laboratórios de Química Analítica e Ambiental da Universidade de Brasília (UnB) e no Laboratório de Análises de Tecidos do Centro de Pesquisa Agropecuária dos Cerrados (CPAC/EMBRAPA), em Planaltina (Distrito Federal).

\section{RESULTADOS E DISCUSSÃO}

Os níveis de mercúrio total detectados nos sedimentos da bacia hidrográfica do rio Bento Gomes em Poconé, de modo geral são baixos (Tab. I). Constatou-se que do total de 69 amostras analisadas, apenas $26 \%(n=18)$ apresentaram concentrações detectáveis. Entre os teores de mercúrio detectáveis, 33,33\% (n=6) se situaram acima do nível considerado natural $\left(0,1 \mu \mathrm{g} \cdot \mathrm{g}^{-1}\right.$ de peso seco), o qual, segundo LACERDA et al. (1987), reflete as condições de áreas não contaminadas. Em 16 amostras foram detectados mais de $0,02 \mu \mathrm{g} \cdot \mathrm{g}^{-1}$ de peso seco, nível citado por LACERDA (1990) como referencial dos rio amazônicos não contaminados. Já em regiōes de garimpo, onde a contaminação tem sido séria, como em Serra Pelada, Gurupi e Tapajós no Pará, e no norte de Mato Grosso, os níveis de mercúrio no sedimento que ultrapassam 0,1 lug.g $g^{-1}$ de peso seco têm sido da ordem de $100 \%$ (Silva et al. 1989).

Tabela I. Níveis de mercúrio ( $\mathrm{kg}_{\mathrm{g}} \mathrm{g}^{-1}$ de peso seco) detectados no sedimento das estações de coleta na bacia de drenagem do rio Bento Gomes (Poconé, Mato Grosso).

\begin{tabular}{|c|c|c|c|}
\hline \multirow{2}{*}{$\begin{array}{c}\text { Estações de } \\
\text { coleta }\end{array}$} & \multicolumn{3}{|c|}{ Época das coletas } \\
\hline & Agosto/89 & Novembro-dezembro/89 & Junho/90 \\
\hline Nascente do rio Bento Gomes & ND & ND & 0,01 a 0,17 \\
\hline Ponte da Cotia & ND a 0,07 & ND & ND \\
\hline Ponte do Morrinho & ND a 0,02 & ND a 0,06 & ND a 0,15 \\
\hline Rio Piranema/rio Bento Gomes & ND & ND a 0,12 & 0,01 a 0,04 \\
\hline Captação d’água de Poconé & ND & ND a 0,13 & ND \\
\hline Córrego dos Padres & ND a 0,24 & ND & ND \\
\hline Córrego Piraputanga & ND a 0,25 & ND a 0,07 & \\
\hline Rio Bento Gomes/Transpantaneira & ND & ND a 0,04 & ND \\
\hline
\end{tabular}

*. Não detectável (ND).

Os níveis de mercúrio mais elevados $\left(0,24\right.$ e $0,25 \mu g \cdot g^{-1}$ de peso seco), que representam 2,5 vezes o limite de contaminação natural do sedimento, ocorreram em amostras coletadas no tanque dos Padres e nas drenagens do córrego Piraputanga, respectivamente, e se caracterizam como depósitos de rejeitos de mineração mais próximos da áreas de garimpo, nestas duas microbacias (Tab. I). Por outro lado, de modo geral, os níveis de mercúrio encontrados no sedimento das demais estações de coleta estão muito próximos dos teores encontrados por LACERDA 
(1990) (não detectáveis a $0,18 \mu \mathrm{g} \cdot \mathrm{g}^{-1}$ de peso seco), em estudos de dispersão de mercúrio no sedimento da bacia de drenagem do tanque dos Padres (Poconé, Mato Grosso). No entanto, os níveis detectados neste estudo situam-se abaixo do teor mais elevado $\left(0,9 \mu \mathrm{g} \cdot \mathrm{g}^{-1}\right.$ de peso seco) registrado por PFEIFFER et al. (1989b) no sedimento de rios do estado do Rio de Janeiro, cujas águas também recebem rejeitos de garimpos. Fraga et al. (1989) encontraram níveis de mercúrio no sedimento dos rios Paraíba do Sul, Muriaré, Paraíha, Preto e Itabapoana (Rio de Janeiro), da ordem de 0,05 a $0,40 \mu g \cdot g^{-1}$ de peso seco, onde a atividade garimpeira também se fez presente. BoLBRINI et al. (1983) encontraram níveis de mercúrio no sedimento dos rios Moggi-Guaçu e Pardo, no estado de São Paulo, que variaram de não detectável a $4,23 \mu \mathrm{g} \cdot \mathrm{g}^{-1}$ e de não detectável a $1,02 \mu \mathrm{g} \cdot \mathrm{g}^{-1}$ de peso seco, respectivamente.

Concentrações extremamente elevadas de mercúrio no sedimento também têm sido registradas na literatura. MALM et al. (1990), apesar de terem encontrado média dos níveis de mercúrio de $10,20 \mu \mathrm{g} \cdot \mathrm{g}^{-1}$ de peso seco $(\mathrm{n}=27)$, chegaram a detectar $157,31 \mu \mathrm{g} \cdot \mathrm{g}^{-1}$ de peso seco, em sedimento de rio localizado em área de floresta na região Amazônica, nas proximidades de garimpos. No rio Madeira, MALM et al. (1990) encontraram teores de mercúrio no sedimento em uma amplitude de variação de 0,03 a $0,35 \mu g \cdot g^{-1}$ de peso seco, com média de $0,13 \pm 0,11 \mu g \cdot g^{-1}$ de peso seco $(n=26)$. Há também registro de mercúrio de 19,8 $\mu \mathrm{g} \cdot \mathrm{g}^{-1}$ de peso seco (PFEIfFER et al. 1989a) em sedimento do rio Mutum Paraná/Madeira (Rondônia), onde a presença de garimpos já constitui séria ameaça ecológica. Segundo LACERDA ét al. (1987), os rios amazônicos não contaminados possuem níveis de mercúrio no sedimento com variação entre 0,05 a $0,28 \mu g_{i} g^{-1}$ de peso seco, enquanto que os contaminados oscilam entre 0,21 a $19,80 \mu \mathrm{g} \cdot \mathrm{g}^{-1}$ de peso seco.

É interessante ohservar que na segunda época de coleta de sedimento (novembro-dezembro/89), realizada nas proximidades da estação de captação de água de Poconé, foi detectado mercúrio no sedimento na concentração de $0,13 \mu \mathrm{g} \cdot \mathrm{g}^{-1}$ de peso seco, nível esse pouco acima do considerado normal. Esta informação serve de alerta para as autoridades sanitárias de Mato Grosso e, de modo especial, de Poconé, e sugere a necessidade de análise mais detalhada do problema, pois isso pode representar indícios de contaminação do sedimento do rio Bento Gomes, emhora ANDRADE et al. (1988) não tenham encontrado relação entre os níveis de mercúrio na água com aqueles detectados no sedimento de um mesmo rio em Goiás.

Os níveis de mercúrio total detectados em partes moles dos moluscos capturados na bacia hidrográfica do rio Bento Gomes, estão apresentados na tabela II.

Os níveis de mercúrio total detectados em partes moles das três espécies de molusco analisadas de modo geral, podem ser considerados também como baixos.

Constatou-se que do total de 54 moluscos analisados, em $30 \%$ deles $(n=16)$ os níveis de mercúrio foram detectáveis. Entre estes, $18,75 \%(n=3)$ continham acima de $0,5 \mu g \cdot g^{-1}$ de peso úmido, que é o limite máximo estabelecido, a partir do qual já pode ocorrer comprometimento da vida aquática (EPA 1972). 
Tabela II. Niveis de mercúrio ( $\mu \mathrm{g} \cdot \mathrm{g}^{-1}$ de peso úmido) detectados nas partes moles de moluscos Ampullariidae, coletados na bacia hidrográfica do rio Bento Gomes (Poconé, Mato Grosso).

\begin{tabular}{|c|c|c|c|c|c|c|}
\hline \multirow{2}{*}{ Espécies } & \multicolumn{3}{|c|}{ Córrego Piraputanga } & \multicolumn{3}{|c|}{ Rio Bento Gomes/Transpantaneira } \\
\hline & Agosto/89 & Nov-Dez/89 & Junho/90 & Agosto/89 & Nov-Dez/89 & Junho/90 \\
\hline Ampullana scalaris & ND a 0,03 & ND a 0.02 & ND a 0.15 & ND & ND a 0,02 & ND a 0.88 \\
\hline Ampullaria canaliculata & ND & ND & ND & ND & ND a 1,16 & ND \\
\hline Marisa planogyra & ND & ND a 0,18 & 0,07 a 0,13 & ND & 0,04 a 0,59 & ND \\
\hline
\end{tabular}

*. Não detectável (ND).

Os níveis de mercúrio constatados nas três espécies de molusco estudadas situaram-se bem próximos daqueles detectados por LACERDA et al. (1987) (não detectáveis a $0,93 \mu \mathrm{g} \cdot \mathrm{g}^{-1}$ de peso úmido), em Ampullaria sp.. em estudo realizado na bacia de drenagem do tanque dos Padres. No entanto, situam-se muito abaixo dos níveis detectados por MIKAC et al. (1985) em outras espécies de moluscos indicadoras de poluição, mas com diferentes dietas e mecanismos de absorção, bem como em condição de elevada contaminação ambiental.

Pode-se também observar que os níveis detectados nos moluscos foram, de modo geral, mais elevados que os encontrados no sedimento. Isto pode significar o início de um processo de biomagnificação de mercúrio. Além disso, a constatação de $30 \%$ de níveis detectáveis nos moluscos e a ocorrência de níveis acima de 0,5 $\mu \mathrm{g} \cdot \mathrm{g}^{-1}$ de peso úmido, pode estar se refletindo no gavião-caramujeiro, que se alimenta basicamente de Ampullaria scalaris e de $A$. canaliculata e no carão que tem, em Marisa planogyra, um dos ítens mais importantes de sua dieta.

A manutenção de boas condições sanitárias na planície de inundação do Pantanal é de extrema relevância ecológica e sócio-econômica, para que seja preservada sua hiodiversidade. Além disso, o Pantanal recebe muitas espécies de aves migratórias, tanto do extremo sul do continente sul-americano como da América do Norte.

Espera-se que os níveis de contaminação por mercúrio detectados no sedimento e em moluscos da bacia hidrográfica do rio Bento Gomes sirvam de alerta e subsídio para as autoridades responsáveis pela preservação e conservação do Pantanal, para que as mesmas se empenhem em substituir o atual processo de extração de outro com mercúrio por outros não lesivos à saúde humana e à integridade dos ecossistemas de toda a bacia do rio Paraguai.

AGRADECIMENTOS. Às diretorias do Centro de Pesquisa Agropecuária dos Cerrados (CPAC). da Empresa Brasileira de Pesquisa Agropecuária, do Fundo Mundial para a Natureza (WWF-Brasil). do Centro Nacional de Recursos Genéticos e Biotecnologia (CENARGEN) e Universidade de Brasília (UnB). pelas facilidades técnico-cientíticas e apoio. À Prefeitura Municipal de Poconé (Mato Grosso), pelo apoio logístico. 


\section{REFERÊNCIAS BIBLIOGRÁFICAS}

Andrade, J.C. DE; M.I.M.S. Bueno \& P.V. SoARES. 1988. The fate of mercury released from prospecting areas ("garimpos") near Guarinos e Pilar de Goiás. An. Acad. Bras. Ci 60 (3): 292-303.

BISHOP, J.N. \& B.P. NEARY. 1974. The form of mercury in freshwater fish, p.25-29. In: Nat. Res. Counc. Canada (ed.). Proc. Int. Transport of Persistent Chemicals in Aquatic Ecosystems. Ottawa.

Boldrini, C.V.; H.B. de PÁdua \& D.N. Pereira. 1983. Contaminação por mercúrio nos rios Mogi-Guaçu e Pardo (SP). Revista DAE, São Paulo, 44 (135).

Braile, P.M. \& J.E.W.A. Cavalcanti. 1979. Manual de tratamento de águas residuárias industriais. São Paulo, CETESB, 764p.

Callister, S.M.; M.R. Winfrey \& R. Michael. 1986. Microbial methylation of mercury in upper Wisconsin river sediments. Water, Air and Soil Pollution 29: 453-465.

Clifton, A.P. \& C.M.G. Vivian. 1975. Retention of mercury from an industrial source in Swansia Bay sediments. Nature 253 (493): 621-622.

EPA. 1972. Water quality criteria. Washington, Environmental Protection Agency, p. 172-178.

Fraga, I.; J.B. Dias \& P.R.P. AraúJO. 1989. Avaliação de impactos e controle ambiental de garimpagem de ouro em leitos de rios do Rio de Janeiro. Rio de Janeiro, ABES, p.252-466.

HANNERS, L. 1968. Experimental investigation on the accumulation of mercury in water organisms. Rep. Inst. Freshwater Res. Drottinghohem 48: 120-176.

HENDERSON, C.A.; A. Inglis \& W.L. JOHNSON. 1972. Mercury residuous in fish, 1969-1970 - National Pesticide Monitoring Program. Pesticide Monitoring Journal 6 (3): 144-150.

JENSEN, S. \& A. JeRnELOV. 1969. Biological methylation of mercury in aquatic organisms. Nature 223 (5207): 753-754.

Kudo, A. \& D.C. Mortimer. 1979. Pathways of mercury uptake by fish from bad sediments. Environmental Pollutions 19 (3): 239-245.

LACERDA, L.D. DE. 1990. Dispersão de mercúrio em uma drenagem afetada por rejeitos de atividade garimpeira em Poconé, Mato Grosso. Cuiahá, CETEM, 11 p.

Lacerda, L.D. DE; W.C. Pfeiffer \& E.G. Silveira. 1987. Contaminação por mercúrio na Amazônia. Avaliação preliminar no rio Madeira, Rondônia. Congresso Brasileiro de Geoquímica 1 (2): 165-169.

LORING, D.H. 1975. Mercury in the sediments of the gulf of St. Lawrence. Can. Jour. Earth Sci. 12: 1219-1237.

Mallas, J. \& N. Benedicto. 1986. Mercury and golding in the Brazilian Amazon. Ambio 15 (4): 248-249.

Malm, O.; W.C. Pfeiffer \& C.M.N. DE SouzA. 1990. Mercury pollutions due to gold mining in the Madeira river hasin. Amazon/Brazil. Ambio 19: 11-15. 
Mikac, N.; M. Picer \& P. SteEgnar. 1985. Mercury distribution in a polluted marine area, ratio of total mercury methylmercury and selenium in sediments, mussels and fish. Water Research 19 (11): 1387-1392.

PFEIFFER, W.C.; L.D. DE LACERDA \& O. MALM. 1989a. Mercury concentrations in inland waters of gold mining areas in Rondonia, Brasil. The Science of the Total Environment 87/88: 233-240.

1989b. Mercury pollution in gold mining areas of Rio de Janeiro. Rio de Janeiro, Universidade Federal do Rio de Janeiro, 4p.

PHillips, D.J.H. 1977. The use of biological indicator to monitor trace metal pollution in marine and stuarine environments a review. Environmental Pollution 13: 281-317.

Ponce, G.A.E.; A.C. Barbosa \& R.O. Ornelas. 1990. Método modificado para a determinação de mercúrio por espectrofotometria de absorção atômica. Anais da Reunião Anual da Sociedade Brasileira de Química. 23p.

Reimers, R.S.: P.A. Krenkel \& A.J. England JR. 1974. Transport and distribution of mercury in sediments. Proc. Int. Conf. Transp. Persistent Cham. Aquatic Ecosystem. Otawa.

RICHINS, R.T. \& A.C. RISSER JR. 1975. Total mercury in water, sediment and soleded ayuatic organisms, Carson River, Nevada - 1972. Pesticide Monitoring Journal. Nevada, 9 (1): 44-54.

SEI, J.M. 1978. Serious mercury contamination of sediments in a Norwegian semi-ciosed hay. Marine Pollution Bulletin 9 (7).

Silva, A.R.B. DA; G.A. Guimarães \& M.Q. DA COSTA. 1989. A contaminação mercurial nos garimpos de ouro da Amazônia. S.I., S.N. III Congresso Brasileiro de Defesa do Meio Ambiente, Rio de Janeiro.

Westoo, G. 1972. Methylmercury as percentage of total mercury in flesh and viscera of Salmon and sea trout of various ages. Science 181 (4099) 567-568.

ZADORY, L. \& P. Mueller. 1981. Potential use of freshwater molluses for monitoring river pollution. Geojournal 5 (5): 433-445.

Recebido em 16.VIII.1994; aceito em 20.X1.1995. 